\title{
The common and specific components of dynamic volatility
}

\author{
Gregory Connor ${ }^{\mathrm{a}, *}$, Robert A. Korajczyk ${ }^{\mathrm{b}}$, Oliver Linton ${ }^{\mathrm{c}}$ \\ ${ }^{a}$ Department of Accounting and Finance, London School of Economics, Houghton Street, \\ London WC2A $2 A E$, UK \\ ${ }^{\mathrm{b}}$ Kellogg School of Management, Northwestern University, 2001 Sheridan Road, \\ Evanston, IL 60208-2001, USA \\ ${ }^{\mathrm{c}}$ Department of Economics, London School of Economics, Houghton Street, London WC2A 2AE, UK
}

Available online 4 March 2005

\begin{abstract}
This paper develops a dynamic approximate factor model in which returns are time-series heteroskedastic. The heteroskedasticity has three components: a factor-related component, a common asset-specific component, and a purely asset-specific component. We develop a new multivariate GARCH model for the factor-related component. We develop a univariate stochastic volatility model linked to a cross-sectional series of individual GARCH models for the common asset-specific component and the purely asset-specific component. We apply the analysis to monthly US equity returns for the period January 1926 to December 2000. We find that all three components contribute to the heteroskedasticity of individual equity returns. Factor volatility and the common component in asset-specific volatility have long-term secular trends as well as short-term autocorrelation. Factor volatility has correlation with interest rates and the business cycle.
\end{abstract}

(C) 2005 Elsevier B.V. All rights reserved.

JEL classification: $\mathrm{C} 13 ; \mathrm{C} 23 ; \mathrm{G} 12$

Keywords: APT; ARCH; Factor models; Principal components; Volatility

\footnotetext{
*Corresponding author.

E-mail addresses: g.connor@1se.ac.uk (G. Connor), r-korajczyk@northwestern.edu (R.A. Korajczyk), lintono@1se.ac.uk (O. Linton).
} 


\section{Introduction}

In the approximate factor model of asset returns developed by Chamberlain and Rothschild (1983), the random return on each of $n$ assets is a linear combination of $k$ common factors plus an asset-specific random return, where $n$ is large and $k$ is small. The asset-specific returns are only weakly correlated, in the sense that the largest eigenvalue of the covariance matrix of asset-specific returns is bounded above for all $n$. This implies that the risk in portfolios with holdings spread thinly over many assets comes only from the common factor returns, not from the asset-specific returns. The factor returns capture nondiversifiable risks, which arise from economywide shocks, whereas the asset-specific returns capture diversifiable risks, which arise from the idiosyncratic movements of individual security prices.

Connor and Korajczyk $(1986,1988)$ develop and apply the asymptotic principal components (APC) method to estimate approximate factor models. They show that, given that the average variance of asset-specific returns is constant through time, the first $k$ eigenvectors of the cross-product matrix of asset returns are a consistent estimate of the $k$ common factors. Scott (1988) and Jones (2001) provide evidence that the cross-sectional average asset-specific variance has considerable time variation. They generalize the APC technique to allow for time-series heteroskedasticity in asset specific returns.

Neither Scott (1988) nor Jones (2001) model the source or nature of the heteroskedasticity in returns since an explicit model is not required for application of their techniques. In this paper, we develop such a model, estimate it, and examine the implications of our findings for asset pricing theory.

We describe a dynamic approximate factor model which includes a threecomponent model of the dynamic heteroskedasticity in asset returns. One component comes from the dynamic heteroskedasticity in factor returns, one from common heteroskedasticity in asset-specific returns, and one from purely assetspecific heteroskedasticity in asset-specific returns. We use the model to decompose the dynamic heteroskedasticity of individual asset returns into factor-related, common asset-specific, and purely asset-specific components. We apply the techniques to monthly US equity returns for the 900-month period January 1926 to December 2000.

We find that all three components contribute to the dynamic heteroskedasticity of individual asset returns. An interesting aspect of the findings is that a large part comes from the common asset-specific component. Given that asset-specific returns capture the idiosyncratic movements of individual security prices, it is interesting that the dynamic volatility of asset-specific return has a large common component. Something about the random technology generating firm-specific cash flows, or the dynamic flow of information about these firm-specific cash flows, or investor's changing reaction to firm-specific news, must underlie this common component in the volatility of asset-specific returns.

We find a strong secular component to common volatility of asset-specific returns. It rises sharply during the Great Depression, declines sharply after the Second World War, and then trends slowly upward (with variable slope) in the Post-War period. 
This is related to the findings of Campbell et al. (2001) concerning secular trends in individual-asset volatility. We find that the typical asset's factor volatility is high during the depression, declines in the early 1940s and (consistent with Campbell et al. (2001)) is relatively stable in the Post-War period. We also relate the volatility components to macroeconomic variates. Factor volatility is strongly anti-cyclical (higher during recessions) and positively correlated with the term spread and default spread in bond markets. The innovation to common asset-specific volatility is not strongly correlated with the macroeconomic variates.

\section{Econometric methodology}

Using the Center for Research in Security Prices (CRSP) monthly dataset of US equity returns, we have a very large cross-section $n$ (21,598 assets including all births and deaths) and a quite large time series $T$ (900 months). We will therefore consider both large $n$ asymptotics and large $T$ asymptotics. Specifically, we will take $n \rightarrow \infty$ and then $T \rightarrow \infty$. ${ }^{1}$ We estimate an approximate factor model by the modification of the Connor and Korajczyk (1986) APC method due to Jones (2001) that allows for time series heteroskedasticity assumed away in Connor and Korajczyk (1986). Bai and $\mathrm{Ng}$ (2002) and Bai (2003) give primitive conditions, including restrictions on the rates of $n$ and $T$, under which the estimated factors are consistent in various senses suitable for our purposes, and we shall comment on this further in a subsequent section.

We then define models for heteroskedasticity in both the common factor and the idiosyncratic components of return. We use the estimated factors and idiosyncratic returns to define empirical counterparts of our model and to estimate the heteroskedasticity parameters.

There is a sizeable literature on factor $\mathrm{ARCH} / \mathrm{GARCH}$ models starting with Engle (1987) and Diebold and Nerlove (1989), and recently reviewed in Sentana (1998). These models are directed purely at heteroskedasticity in the common factor, while we also model the idiosyncratic heteroskedasticity, identification being achieved by invoking the large cross-section assumption. We comment below on the differences between our model and these models.

There have been a number of other advances in the estimation and specification of dynamic factor models in recent years. Forni and Reichlin (1998), and Forni et al. (2000) have developed and applied dynamic factor models, where the factors have an autoregressive structure in the mean. This type of dynamic factor model is

\footnotetext{
${ }^{1}$ Given the large cross-section and moderately large time series, it seems reasonable to employ asymptotic approximations that assume $n \rightarrow \infty$ and $T \rightarrow \infty$ in such a way that $n / T \rightarrow \infty$ (although for some purposes we do not need large $T$ ). This amounts to a pathwise limit approach where $T=T(n)$ for some function $T$. Under certain additional conditions, that are likely to be satisfied in our case, the pathwise limit is the same as the sequential limit in which: first $n \rightarrow \infty$ and then $T \rightarrow \infty$. The sort of conditions required include restrictions on the rate at which $n / T \rightarrow \infty$ and a so-called tightness condition. This sort of multi-index asymptoptics are discussed in Phillips and Moon (1999). See also Bai and Ng (2002).
} 
particularly useful in macroeconomic applications where factors have strong predictability in their means. We shall not model any dependence in the mean of the factors but will focus on the volatility structure. This is more relevant for our financial application since return factors have little or no predictability in their means, due to efficient markets, but can have strong predictability in their volatilities.

Ahn et al. (2001) and Pesaran (2002) have discussed estimation of a factor model in which some factors are directly observed and others are not. They both propose a more general class of methods that uses both first and second moment information. They focus on the case where $n$ is large and $T$ is small. Nevertheless, their estimation strategy is valid in our case.

\subsection{Review of Connor-Korajczyk and Jones}

Let $r_{t}$ denote the $n$-vector of excess returns on $n$ assets at time $t$. We assume that returns follow an approximate factor model with fixed $n \times k$ exposure matrix $B, k$ random factors $f_{t}$ and $n$ asset-specific returns $\varepsilon_{t}$ :

$$
r_{t}=B f_{t}+\varepsilon_{t} \text {. }
$$

Let $\|X\|$ denote the operator norm of any matrix $X$ (equal to the maximum eigenvalue for a symmetric positive definite matrix). We do not assume that $f_{t}, \varepsilon_{t}$ are i.i.d., but impose the following weaker conditions on (1):

$$
\begin{aligned}
& E\left[\varepsilon_{t} \mid f_{\tau}\right]=0 \text { for all } t, \tau . \\
& \lim _{n \rightarrow \infty} \frac{1}{n} B^{\prime} B=M \text { a nonsingular matrix. } \\
& \lim _{n \rightarrow \infty}\left\|E\left[\varepsilon_{t} \varepsilon_{t}^{\prime}\right]\right\|=c<\infty .
\end{aligned}
$$

The estimation method we use for the factors $\left\{f_{t}\right\}_{t=1}^{T}$, APC, relies on the law of large numbers applied to $n^{-1} \varepsilon_{t}^{\prime} \varepsilon_{\tau}$ where $n$ is large. Sufficient conditions for this to apply are given in Connor and Korajczyk (1993): these include restrictions, i.e., mixing conditions, on the cross-sectional dependence and moment conditions. In the temporally heteroskedastic case of this paper, we require these conditions to hold uniformly over $t$. Here, we simply assume that the relevant law of large numbers holds, i.e.

$$
p \lim _{n \rightarrow \infty} \frac{1}{n} \varepsilon_{t}^{\prime} \varepsilon_{\tau}= \begin{cases}0 & \text { for } \tau \neq t, \\ \phi_{t}>0 & \text { for } \tau=t .\end{cases}
$$

Let $R$ denote the $n \times T$ matrix of excess returns on the $n$ assets over a time period of length $T$. Let $F$ denote the $k \times T$ matrix of common factor returns and $E$ be the $n \times T$ matrix of asset specific returns for the same sample. Let $\widehat{\Omega}=R^{\prime} R / n$ denote the $T \times T$ cross-product matrix of returns. We use $\operatorname{Diag}[\cdot]$ to denote the function that transforms a $T$-vector into a $T \times T$ diagonal matrix and $\operatorname{diag}[\cdot]$ (with a lower case $d$ ) 
for the function that changes the diagonal components of a $T \times T$ diagonal matrix into a $T$-vector. Taking the probability limit of the cross-product matrix as $n$ goes to infinity, and using (1)-(5):

$$
p \lim _{n \rightarrow \infty} \widehat{\Omega}=\Omega=F^{\prime} M F+\operatorname{Diag}\left[\phi_{1}, \ldots, \phi_{T}\right]
$$

In the special case considered by Connor and Korajczyk where asset-specific returns are identically distributed through time we have $p \lim _{n \rightarrow \infty} E^{\prime} E / n=\phi I_{T}$, where $\phi$ is a constant and $I_{T}$ denotes the $T \times T$ identity matrix. Note that $F^{\prime} M F$ has $k$ eigenvectors corresponding to nonzero eigenvalues, and that these eigenvectors are equal to $L F$ for some nonsingular $k \times k$ matrix $L$. Also, note that the eigenvectors of $F^{\prime} M F+\phi I_{T}$ equal the eigenvectors of $F^{\prime} M F{ }^{2}$ Using the fact that the eigenvector function is a smooth function of a nonsingular matrix this gives, for the case $\phi_{t}=\phi$ for all $t$ :

$$
p \lim _{n \rightarrow \infty} \operatorname{eigvec}_{k}[\widehat{\Omega}]=\operatorname{eigvec}_{k}\left[p \lim _{n \rightarrow \infty} \widehat{\Omega}\right]=L F .
$$

Eq. (7) is the basic result from Connor and Korajczyk: under their assumptions, the first $k$ eigenvectors of the cross-product matrix converge to a rotation of the factor returns. Bai (2003, Theorem 1) derives conditions (including restrictions on the relative growth rates of $n$ and $T$ ) under which the eigenvectors provide consistent estimates of $L F$. Jones (2001) generalizes to the heteroskedastic case by letting the limit of the cross-product matrix of asset-specific returns, $p \lim _{n \rightarrow \infty} E^{\prime} E / n$, be diagonal rather than scalar. In particular, suppose that we observe this diagonal (rather than scalar) matrix of cross-sectional mean asset-specific variances $\operatorname{Diag}[\Phi]$, where $\Phi=\left[\phi_{1}, \ldots, \phi_{T}\right]$, then given (6) we have

$$
\begin{aligned}
& \underset{n \rightarrow \infty}{p} \lim _{\operatorname{eigec}_{k}}\left\{\operatorname{Diag}[\Phi]^{-1 / 2} \widehat{\Omega} \operatorname{Diag}[\Phi]^{-1 / 2}\right\} \operatorname{Diag}[\Phi]^{1 / 2} \\
& \quad=\operatorname{eigvec}_{k}\left\{\operatorname{Diag}[\Phi]^{-1 / 2} F^{\prime} \operatorname{MFDiag}[\Phi]^{-1 / 2}+I_{T}\right\} \operatorname{Diag}[\Phi]^{1 / 2}=L F .
\end{aligned}
$$

We follow Jones in using (8) to estimate the factors and asset-specific returns. Our methodological contribution is to develop an explicit model for the heteroskedasticity in returns, and to estimate this three-component model of heteroskedasticity together with the approximate factor model.

\subsection{A two-component model of heteroskedasticity in asset-specific returns}

As mentioned in the introduction, the presence of heteroskedasticity in assetspecific returns is not surprising, but the nature of the heteroskedasticity is

\footnotetext{
${ }^{2}$ To see this, just write out the eigendecomposition $F^{\prime} M F=Q \Lambda Q^{\prime}$, where $Q, \Lambda$ are $T \times T$ matrices with $Q Q^{\prime}=I_{T}$ and $\Lambda$ being diagonal with all but the first $k$ diagonal elements being zero. Then, $F^{\prime} M F+\phi I_{T}=$ $Q\left[\Lambda+\phi I_{T}\right] Q^{\prime}$, i.e., the eigenvectors of $F^{\prime} M F+\phi I_{T}$ are the same as those of $F^{\prime} M F$ by the uniqueness of the eigendecomposition. If we normalize $F$ so that $F^{\prime}$ is the first $k$ columns of $Q$, corresponding to nonzero eigenvalues, we are implicitly normalizing $M$ as the sub-block of nonzero elements of $\Lambda$.
} 
interesting. In particular, there is a strong commonality in the heteroskedasticity, so that the average across $n$ assets of squared asset-specific return varies through time.

We capture the commonality in asset-specific volatilities with a univariate timeseries model for the cross-sectional mean-square asset-specific return $\phi_{t}$ (hereafter called common asset-specific variance). By construction, this variate is always positive. We assume that its logarithm follows a nonparametric local trend model with stationary innovations:

$$
\log \phi_{t}=g_{\phi}(t / T)+u_{t}, \quad a(L) u_{t}=b(L) \psi_{t},
$$

where $\psi_{t}$ is a stationary process, and the lag polynomial $a(L)=1-a_{1} L-\ldots a_{p} L^{p}$ has roots outside the unit circle. The 'local' trend term $g_{\phi}(t / T)$ is motivated by the graphical evidence for secular trends shown later (Fig. 1a). We do not wish to restrict the functional form of $g_{\phi}($.$) , and use semiparametric methods to determine its shape.$ At the same time we allow for short run dynamics through the polynomials $a(L), b(L)$. The central version of this model has $\psi_{t}$ being a martingale difference sequence, i.e., $E\left(\psi_{t} \mid I_{t-1}\right)=0$, where $I_{t-1}$ is lagged information. We also consider the case where $\psi_{t}$ is identified off a quantile restriction, so that quant ${ }_{\vartheta}\left(\psi_{t} \mid I_{t-1}\right)=0$ for some $\vartheta \in(0,1)$, where quant ${ }_{\vartheta}$ is the $\vartheta$-quantile function. The motivation to consider the quantile model is its robustness with respect to large observations, which we certainly have during the Great Depression period. In both specifications we allow for conditional heteroskedasticity in $\psi_{t}$. We give some more detail below on how the function $g_{\phi}($.$) was estimated and which orders of a, b$ were chosen.

In either the mean-identified or quantile-identified model, the dominant part is the nonparametric trend function in terms of interpretation and statistical difficulty. We conducted some unit root tests below and find against a stochastic trend (unit root) alternative, and in favor of our deterministic trend specification. We have tried a number of other specifications for $\phi_{t}$, including: specifications in levels, including monthly dummy variables, and fitting the evident heteroskedasticity in $\phi_{t}$ with volatility models, but the basic features of the data remain in these other specifications.

We note that the particular form of the time-series model for $\phi_{t}$ has no effect on the estimates for the other components of volatility.

Next we model the purely asset-specific volatility. Let $\eta_{t}$ denote the $n$-vector timeseries of volatility-specific, asset-specific returns. The $n$-vector of asset-specific returns at time $t$ is the product of the scalar common volatility and the $n$-vector of volatility-specific, asset-specific returns:

$$
\varepsilon_{t}=\phi_{t}^{1 / 2} \eta_{t}
$$

Since the scale of the two components in product (11) is indeterminate we normalize $\eta_{t}$ to have unit expected inner-product

$$
\frac{1}{n} E\left[\eta_{t}^{\prime} \eta_{t}\right]=1
$$

Eqs. (10)-(12) are a type of stochastic volatility model, where $\phi_{t}$ is the state variable generating time-varying common volatility. One difference from fixed-dimensional 


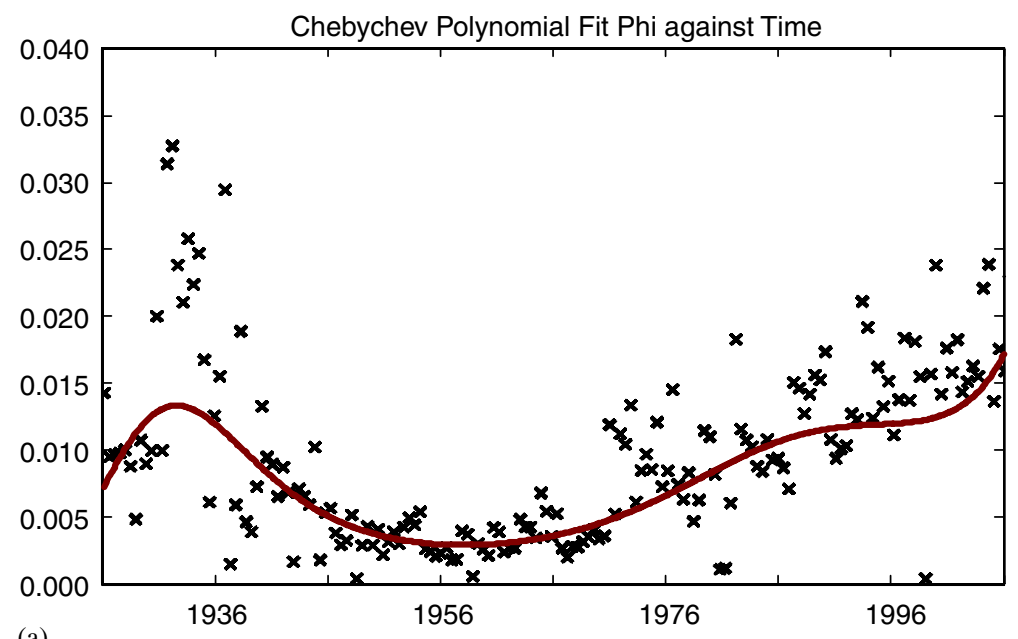

(a)

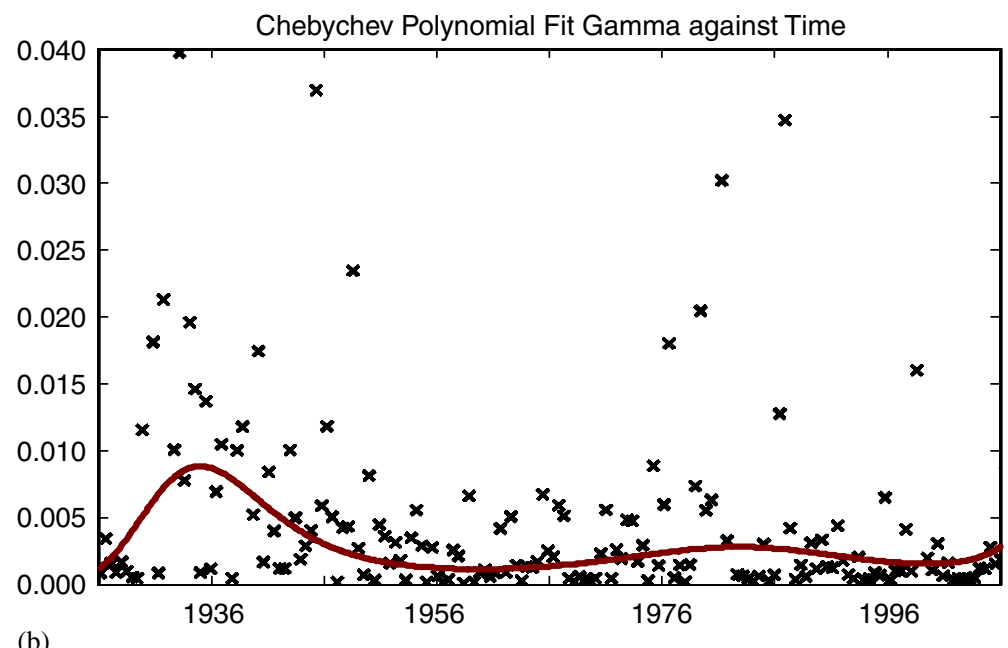

Fig. 1. (a) Shows Chebychev Polynomial fit of $\phi_{t}$ against time along with data points; (b) shows Chebychev Polynomial fit of $\gamma_{t}$ against time along with data points.

stochastic volatility models is that the state variable in this stochastic volatility model is approximately observable, by taking a probability limit for large $n$.

Although, by construction, $\eta_{i t}$ has no common volatility across assets, it can still have time-series autoregressive heteroskedasticity on an individual-asset basis. To capture this, we assume that $\eta_{i t}$ follows a standard univariate volatility model for each $i$

$$
\eta_{i t}=h_{i t}^{1 / 2} z_{i t}
$$


where $h_{i t}$ is time-varying variance. We consider three models for this purely assetspecific volatility. The first is a $\operatorname{GARCH}(1,1)$ model (Bollerslev, 1986):

$$
h_{i t}=\omega_{0 i}+\omega_{1 i} h_{i t-1}+\omega_{2 i} \eta_{i t-1}^{2},
$$

where $\left(\omega_{0 i}, \omega_{1 i}, \omega_{2 i}\right)$ are unknown parameters varying freely from asset to asset.

The second is the GJR model (Glosten et al., 1993):

$$
h_{i t}=\omega_{0 i}+\omega_{1 i} h_{i t-1}+\omega_{2 i} \eta_{i t-1}^{2} 1\left(\eta_{i t-1}<0\right)+\omega_{3 i} \eta_{i t-1}^{2} 1\left(\eta_{i t-1} \geqslant 0\right) .
$$

where $1(x)$ has the value 1 if the condition $x$ is true and zero otherwise. The third alternative is the EGARCH model (Nelson, 1991):

$$
\log \left(h_{i t}\right)=\omega_{0 i}+\omega_{1 i} \log \left(h_{i t-1}\right)+\omega_{2 i}\left(\left|\eta_{i t-1}\right| / h_{i t-1}-\omega_{3 i} \eta_{i t-1} / h_{i t-1}\right) .
$$

For all three models, we suppose that $z_{i t}$ is an innovation sequence that has mean zero and variance one, conditional on past information. We can allow for general cross-section dependence in $z_{i t}$ and some temporal dependence and heterogeneity (semi-strong GARCH), although the central model here is i.i.d. across time and asset. We are primarily interested in weakly stationary processes because only in this case does the unconditional variance of $r_{t}$ exist. This entails certain restrictions on the parameters of (14)-(16). In (14) we suppose that $\omega_{0 i}>0, \omega_{1 i}, \omega_{2 i} \geqslant 0$ for positivity of $h_{i t}$, and $\omega_{1 i}+\omega_{2 i} \leqslant 1$ for weak stationarity. In the GJR model, the positivity restrictions are the same as $\operatorname{GARCH}(1,1)$ with the addition of $\omega_{3 i} \geqslant 0$. The stationarity restrictions are more complicated and depend on the distribution of $z_{i t}$ : the central case is where $z_{i t}$ is symmetric about zero in which case it is necessary and sufficient that $\omega_{1 i}+\left(\omega_{2 i}+\omega_{3 i}\right) / 2 \leqslant 1$ for weak stationarity. In the EGARCH model it is not necessary to impose any restrictions on $\omega_{0 i},, \omega_{2 i}, \omega_{3 i}$ for positivity of variance, and for both weak stationarity and strong stationarity it suffices that $\left|\omega_{1 i}\right|<1$ (under moment conditions on $z_{i t}$ ). See Carrasco and Chen (2002) for more detailed discussion.

\subsection{A one-component model of heteroskedasticity in common factors}

The Diebold and Nerlove (1989) factor ARCH model specifies an ARCH process directly for each of the unobserved factors $f_{t} \cdot{ }^{3}$ The fit of the factor model of returns (1) is unaffected if a $k$-vector of factor variates $f_{t}$ is replaced with any nonsingular rotation $L f_{t}$ as long as the exposure matrix $B$ is replaced by $B L^{-1}$. However, the dynamic volatility process followed by any individual factor is not invariant with respect to a rotation. Hence, volatility models which apply to the individual factors are problematic, unless a particular, economically meaningful, rotation is chosen to define the individual factors.

We develop a univariate measure of factor volatility that is invariant to factor rotations. In particular, note that the quadratic product $f_{t}^{\prime}\left(\frac{1}{n} B^{\prime} B\right) f_{t}$ is rotation invariant and aggregates in a useful way the volatility of all the factors. Using the assumed convergence of $\frac{1}{n} B^{\prime} B$ we have $\lim _{n \rightarrow \infty} f_{t}^{\prime}\left(\frac{1}{n} B^{\prime} B\right) f_{t}=f_{t}^{\prime} M f_{t}$. This quadratic

\footnotetext{
${ }^{3}$ Engle (1987) instead replaces $f_{t}$ by observed portfolios.
} 
product has a useful relationship to $\phi_{t}$ defined above, in particular,

$$
p \lim _{n \rightarrow \infty} \frac{1}{n} r_{t}^{\prime} r_{t}=f_{t}^{\prime} M f_{t}+\phi_{t}=\gamma_{t}+\phi_{t}
$$

In words, cross-sectional mean-square excess return approximately equals the sum of cross-sectional mean-square common-factor-related return and cross-sectional mean-square asset-specific return. This approximation ignores any observed crosssectional covariance between common factor and asset-specific returns, since this covariance will be small for large $n$. We suppose that

$$
\log \gamma_{t}=g_{\gamma}(t / T)+v_{t}, \quad c(L) v_{t}=d(L) \xi_{t},
$$

where $\xi_{t}$ is a stationary process, and the lag polynomial $c(L)=1-a_{1} L-\ldots a_{p} L^{p}$ has roots outside the unit circle. We allow the function $g_{\gamma}($.$) to have a general shape.$ Similar considerations apply to the time series process for $\gamma_{t}$ as they did to the time series process for $\phi_{t}$.

\subsection{Overview}

In this section we give a discussion of the full model and the relevant asymptotic theory for our estimates. The full model is (1), (10), (11), (13), (14), (17). The basic unmodelled innovation processes are $\psi_{t}, \xi_{t}$, and the parameters to be determined include the factors $f_{t}$, the dynamic parameters in the lag polynomials $a, b, c, d$, the functions $g_{\gamma}, g_{\phi}$, and the parameters of the individual volatility models, $\left\{\omega_{j i}\right\}$. Also to be determined are the number of factors to include and the orders of the various dynamic process and the shapes of the trend functions. In view of the enormous sample size at our disposal and the large number of parameters to be estimated we do estimation of the separate parts of our model one at a time rather than try to jointly optimize. It may be possible to improve the efficiency of some of our procedures, but a more complicated procedure would carry some risks due to the consequences of misspecification.

Under (1)-(12) we have that $p \lim _{n \rightarrow \infty} \widehat{F}=F$ and $p \lim _{n \rightarrow \infty} \widehat{\Phi}=\Phi$ by the continuous mapping theorem for each $T$. This result can be extended to $\max _{1 \leqslant t \leqslant T}\left\|\widehat{f}_{t}-f_{t}\right\|=o_{p}(1)$ and $\max _{1 \leqslant t \leqslant T}\left\|\widehat{\phi}_{t}-\phi_{t}\right\|=o_{p}(1)$ when $T$ is allowed to grow with $n$, under some restrictions on the growth of $T, n$; see Bai (2003). Regarding the parameters of our time series models, for example the parameters of $g_{\phi}(),. a(L)$, and $b(L)$, we will compute standard errors based on a standard root- $T$ consistency theory. In order for the estimation error at the factor estimation stage not to affect the subsequent time series estimation, we require the stronger uniform convergence results:

$$
\max _{1 \leqslant t \leqslant T}\left\|\widehat{f}_{t}-f_{t}\right\|=o_{p}\left(T(n)^{-1 / 2}\right) \quad \text { and } \quad \max _{1 \leqslant t \leqslant T}\left\|\widehat{\phi}_{t}-\phi_{t}\right\|=o_{p}\left(T(n)^{-1 / 2}\right) .
$$

These conditions can be satisfied under strong restrictions on the rates at which $n, T$ increase, see Bai and $\mathrm{Ng}$ (2002) and Bai (2003). Specifically, a necessary condition is that $n / T^{2} \rightarrow \infty$. Given the very large cross-section we have, this condition seems 
quite reasonable. When the required regularity conditions are satisfied, our time series estimates are $\sqrt{T}$ consistent and the usual distribution theory holds.

\section{Data and estimation details}

We use 900 months of excess returns data on 21,598 (total) US equities for the period January 1926 to December 2000 from the CRSP monthly returns data file. For the estimation of the factor model, we divide the period into fifteen, 60-month subperiods. Connor and Korajczyk (1993) find between three and six pervasive factors for the CRSP monthly data whereas Bai and $\mathrm{Ng}$ (2002), relying on a different test but similar CRSP data, argue for only two pervasive factors. Jones (2001) used five factors. After experimenting with 5, 10 and 15 factors, we decided to use five as the number of pervasive factors.

We use the Connor and Korajczyk (1987) definition of the cross-product matrix to account for missing observations:

$$
\Omega_{t \tau}=\frac{1}{n_{t \tau}} \sum_{i=1}^{n_{t \tau}} r_{i t} r_{i \tau},
$$

where $n_{t \tau}$ is the number of firms with returns in both months $t$ and $\tau$ and the index runs over these firms. Table 1 shows the minimum, maximum and average of $n_{t t}$ and $n_{t \tau} t \neq \tau$ within each 60 -month subperiod.

Table 1

Number of return observations for factor estimation

\begin{tabular}{|c|c|c|c|c|c|c|}
\hline \multirow[t]{2}{*}{ Subperiod } & \multicolumn{3}{|c|}{ Number of assets per month: $n_{t t}$} & \multicolumn{3}{|c|}{ Number of assets in cross-products: $n_{t \tau} t \neq \tau$} \\
\hline & Minimum & Average & Maximum & Minimum & Average & Maximum \\
\hline $1926 / 1-1930 / 12$ & 494 & 610 & 730 & 429 & 539 & 722 \\
\hline $1931 / 1-1935 / 12$ & 688 & 703 & 725 & 636 & 676 & 721 \\
\hline $1936 / 1-1940 / 12$ & 708 & 757 & 780 & 642 & 723 & 778 \\
\hline $1941 / 1-1945 / 12$ & 781 & 804 & 842 & 749 & 783 & 838 \\
\hline $1946 / 1-1950 / 12$ & 847 & 939 & 1004 & 826 & 907 & 1003 \\
\hline $1951 / 1-1955 / 12$ & 1003 & 1031 & 1044 & 944 & 1006 & 1043 \\
\hline $1956 / 1-1960 / 12$ & 1041 & 1060 & 1101 & 939 & 1013 & 1099 \\
\hline $1961 / 1-1965 / 12$ & 1100 & 1756 & 2118 & 961 & 1463 & 2109 \\
\hline $1966 / 1-1970 / 12$ & 2111 & 2188 & 2344 & 1625 & 1953 & 2328 \\
\hline $1971 / 1-1975 / 12$ & 2345 & 3958 & 5482 & 2007 & 3131 & 5422 \\
\hline $1976 / 1-1980 / 12$ & 4510 & 4683 & 4826 & 3461 & 4232 & 4800 \\
\hline $1981 / 1-1985 / 12$ & 4771 & 5364 & 5880 & 3335 & 4575 & 5830 \\
\hline $1986 / 1-1990 / 12$ & 5471 & 5913 & 6266 & 3423 & 5007 & 6214 \\
\hline $1991 / 1-1995 / 12$ & 5686 & 6304 & 7087 & 3915 & 5324 & 7002 \\
\hline $1996 / 1-2000 / 12$ & 6664 & 7293 & 7687 & 4012 & 6072 & 7628 \\
\hline
\end{tabular}

Note: Within each 60-month subperiod, the table shows the minimum, average and maximum number of assets each month (columns two to four) and the minimum, average and maximum number of assets with returns in months $t$ and $\tau$ for all $t \neq \tau$. 
The first estimation step produces $n$-consistent estimates of the $k \times T$ matrix of factor returns $F$ and common asset-specific variances $\Phi=\left(\phi_{1}, \ldots, \phi_{T}\right)^{\prime}$ on each of the 60 -month subperiods. The second-stage estimates come from essentially the same procedure as in Jones (2001). Let $\widehat{\Lambda}$ denote the $k \times k$ diagonal matrix of the first $k$ eigenvalues of the cross-product matrix $\widehat{\Omega}$. We have

$$
\begin{aligned}
& \widehat{F}=\operatorname{eigvec}_{k}\left\{\operatorname{Diag}[\widehat{\Phi}]^{-1 / 2} \widehat{\Omega} \operatorname{Diag}[\widehat{\Phi}]^{-1 / 2}\right\} \operatorname{Diag}[\widehat{\Phi}]^{1 / 2}, \\
& \widehat{\Phi}=\operatorname{diag}\left[\widehat{\Omega}-\widehat{F}^{\prime} \widehat{\Lambda}^{2} \widehat{F}\right] .
\end{aligned}
$$

The system is only iteratively defined since the estimation of $\widehat{F}$ in (19) requires $\widehat{\Phi}$ from (20) and vice-versa. We begin with $\widehat{\Phi}=I_{T}$ in (19) and iterate between the two estimation problems, as suggested in Jones (2001). ${ }^{4}$

The estimation of the common asset-specific variances $\Phi=\left(\phi_{1}, \ldots, \phi_{T}\right)^{\prime}$ in (20) assumes balanced panels; the extension to unbalanced panels is straightforward. We regress each asset's excess return on a constant and the previous-iteration $\widehat{F}$ and keep the time-series regression residuals $\widehat{\varepsilon}_{i t}$. For this set of regressions we use all assets with at least 36 months of returns within the relevant subperiod. The cross-sectional mean square of $\widehat{\varepsilon}_{i t}$ at time $t$ is $\widehat{\phi}_{t}$.

\section{Empirical results}

\subsection{Factor estimation}

We first report on the convergence of our iterative factor extraction method. We calculate the cross-sectional average of adjusted $R^{2}$ from the time-series regressions of each asset's excess return on the five factor returns. Note that the first iteration is the uncorrected APC procedure and the final iteration is the Jones procedure. For most of the subperiods (14 out of 15, not shown), the Jones procedure has a lower average $R^{2}$ than the uncorrected procedure, but the difference tends to be small. For each iteration, Table 2, columns two to four, show the minimum, maximum and average values of the average individual-asset $R^{2}$ statistics, across the 15 subperiods. The minimum and average values are slightly higher with the uncorrected procedure and the maximum is (very slightly!) higher with the Jones procedure. ${ }^{5}$

To test the convergence of the iterative algorithm, we run a time-series regression of each factor return on all of the five factors from the previous iteration, and

${ }^{4}$ In the balanced panel case, this procedure is equivalent to minimizing the criterion

$$
\sum_{t=1}^{T} \sum_{i=1}^{n}\left(r_{i t}-b_{i}^{\prime} f_{t}\right)^{2} \phi_{t}^{-1}+\sum_{t=1}^{T} \log \phi_{t}
$$

with respect to $\left(\phi_{1}, \ldots, \phi_{T}, f_{1}, \ldots, f_{T}\right)$ and $\left(b_{1}, \ldots, b_{n}\right)$ subject to the identifying restrictions that $F^{\prime} F / T=$ $I_{T}$; see Bai and $\mathrm{Ng}$ (2002) for the homoskedastic special case.

${ }^{5}$ Scott (1988) finds that the modified APC method gives results similar to APC while Jones (2001) finds that the modification improves empirical fit of the extracted factors. ITG (2002, Section 7.3) discusses the out-of-sample performance of the alternative estimators. 
Table 2

Cross-sectional average individual-asset adjusted $R^{2} \mathrm{~s}$, and convergence criteria for iterative factor estimates

\begin{tabular}{lllll}
\hline \multirow{2}{*}{ Iteration number } & \multicolumn{2}{l}{ Cross-sectional average individual-asset adjusted $R^{2} \mathrm{~s}$} & \multirow{2}{*}{ Convergence criteria } \\
\cline { 2 - 4 } & Minimum & Average & Maximum & \\
\hline 1 & .137 & .365 & .649 & NA \\
2 & .132 & .361 & .650 & .252 \\
3 & .131 & .360 & .650 & .847 \\
4 & .131 & .359 & .650 & .933 \\
5 & .131 & .358 & .650 & .964 \\
6 & .131 & .358 & .650 & .971 \\
7 & .131 & .358 & .650 & .988 \\
8 & .131 & .358 & .650 & .999 \\
9 & .131 & .358 & .650 & 1.000 \\
10 & .131 & .358 & .650 & 1.000 \\
\hline
\end{tabular}

Note: Time-series regression of each asset against all five factors is applied to each asset with at least 36 observations within each 60 -month factor estimation subperiod. The cross-sectional average $R^{2}$ is calculated across all the regressions within each 60 -month subperiod. The minimum, average and maximum values of these cross-sectional average $R^{2}$ s are taken across the 15 subperiods. The convergence criteria is the minimum adjusted $R^{2}$ from the regression of each factor on the five factors from the previous iteration. The minimum is taken across all five factors and all 15 subperiods. To save space, only the first 10 iterations are shown in the table since iterations 11-15 have identical values to iteration 10 .

calculate the minimum of the adjusted $R^{2}$ s across these five regressions. We then take a minimum across the 15 subperiods and use this as the convergence criterion. This minimum $R^{2}$ is displayed in the last column of Table 2 . In all subperiods the algorithm converges with high precision after no more than nine iterations.

\subsection{Volatility patterns and trends}

We next report the results of our time-series model for $\phi_{t}$, the common assetspecific variance. Fig. 1a shows the time series of $\phi_{t}$ (the dots in Fig. 1a). The presence of strong secular trends seems obvious from the graph. However, there are no obvious structural breaks associated with the 60 -month factor model estimation subperiods, and so we use the full 900-month sample for this and later estimation stages. ${ }^{6}$ In view of the potential large influence of the late 1920s and early 1930 s we also recomputed our estimators for the sub period 1946:01 onwards for the meanidentified model. Also for robustness reasons we estimated the quantile-identified model using the full sample.

\footnotetext{
${ }^{6} \mathrm{We}$ have also re-estimated our main time series equations with dummy variables that are 1 at the start of each of the subperiods and zero elsewhere. The substantive results are not affected by the inclusion of the dummy variables, and only one or two dummy variables themselves are significant at the $5 \%$ level in any given equation.
} 
Table 3

Unit root tests

\begin{tabular}{|c|c|c|c|c|c|}
\hline \multirow[t]{2}{*}{ Includeds } & \multirow[t]{2}{*}{ no. lags } & \multicolumn{2}{|l|}{ Levels } & \multicolumn{2}{|l|}{$\operatorname{Logs}$} \\
\hline & & $\mathrm{ADF}$ & $\mathrm{PP}$ & $\mathrm{ADF}$ & PP \\
\hline \multirow[t]{9}{*}{ Cons only } & 0 & -13.801 & -13.801 & -15.371 & -15.371 \\
\hline & 1 & -8.869 & -12.819 & -9.869 & -14.547 \\
\hline & 2 & -6.658 & -12.808 & -7.818 & -14.722 \\
\hline & 3 & -5.134 & -13.043 & -6.438 & -15.045 \\
\hline & 4 & -4.544 & -13.528 & -5.520 & -15.480 \\
\hline & 5 & -4.212 & -14.011 & -4.800 & -15.941 \\
\hline & 6 & -3.434 & -14.408 & -4.274 & -16.432 \\
\hline & 7 & -3.218 & -14.913 & -3.827 & -16.919 \\
\hline & 8 & -2.711 & -15.346 & -3.569 & -17.420 \\
\hline \multirow[t]{9}{*}{ Cons\&trend } & 0 & -14.758 & -16.225 & -16.225 & -16.225 \\
\hline & 1 & -9.577 & -13.895 & -10.512 & -15.507 \\
\hline & 2 & -7.251 & -13.944 & -8.384 & -15.717 \\
\hline & 3 & -5.653 & -14.221 & -6.957 & -16.059 \\
\hline & 4 & -5.034 & -14.733 & -6.002 & -16.503 \\
\hline & 5 & -4.703 & -15.240 & -5.267 & -16.971 \\
\hline & 6 & -3.898 & -15.662 & -4.720 & -17.466 \\
\hline & 7 & -3.681 & -16.187 & -4.268 & -17.957 \\
\hline & 8 & -3.158 & -16.642 & -4.000 & -18.461 \\
\hline
\end{tabular}

Note: This gives the values of the ADF and PP test statistics for the null hypothesis of a unit root. The test statistics are computed for the case with a constant (cons only) included and the case with both a constant and linear trend (cons and trend) included, and for a number of choices of short run dynamics (i.e., lags $k$ ). The critical values are given below: Critical value without trend: $1 \%$ is $-3.440,5 \%$ is $-2.865,10 \%$ is -2.569 ; Critical value with trend: $1 \%$ is $-3.973,5 \%$ is $-3.417,10 \%$ is -3.131 .

Our local trend model (10) has quite different implications from say a unit root process, and we first seek to establish which of these two model types is more consistent with the data. We report the results of some standard unit root tests in Table 3. We examine the level and logs using the Augmented Dickey-Fuller (ADF) test and Phillips-Perron (PP) tests, including either a constant or a constant and linear trend, as well as a number of lags to represent the short run dynamics. There seems to be very little evidence of a unit root in any of the specifications, especially when using the PP test. Therefore, we feel that our deterministic trend model is well supported by the data.

We estimate (10) by two different methods. First, we used Hildreth-Lu OLS timeseries regression. In this approach we assume that the deterministic trend function $g_{\phi}($.$) belongs to a class of time-series polynomials, in particular, the Chebychev$ polynomial class. The number of terms was selected by the Akaike criterion. In the full sample case this yielded 5 terms. In the post-war subsample 4 polynomials were selected. We experimented also with the order of the autoregressive process and found that 2 and 4 lags, respectively, were sufficient to induce whiteness in the 
Table 4

Time-series models of common asset-specific variance and common factor variance

\begin{tabular}{|c|c|c|c|c|c|c|c|c|c|c|}
\hline & $b_{0}$ & $b_{1}$ & $b_{2}$ & $b_{3}$ & $b_{4}$ & $b_{5}$ & $a_{1}$ & \multicolumn{3}{|l|}{$a_{2}$} \\
\hline \multicolumn{11}{|c|}{$\begin{array}{l}\text { Panel A: Common asset-specific variance } \\
\text { January } 1926 \text {-December } 2000\end{array}$} \\
\hline Coefficient & -4.67 & .439 & .670 & -.052 & -.170 & .361 & .191 & .100 & & \\
\hline$t$-statistic & -148.5 & 8.32 & 14.0 & -0.99 & -3.52 & 7.63 & 2.92 & 1.76 & & \\
\hline \multicolumn{11}{|c|}{ January 1946-December 2000} \\
\hline \multirow{3}{*}{$\begin{array}{l}\text { Coefficient } \\
t \text {-statistic }\end{array}$} & -2.97 & -2.75 & 3.18 & -1.77 & .723 & -.025 & .160 & .139 & & \\
\hline & -1.63 & -.81 & 1.23 & -1.07 & .90 & -.09 & 1.89 & 1.95 & & \\
\hline & $b_{0}$ & $b_{1}$ & $b_{2}$ & $b_{3}$ & $b_{4}$ & $b_{5}$ & $a_{1}$ & $a_{2}$ & $a_{3}$ & $a_{4}$ \\
\hline \multicolumn{11}{|c|}{$\begin{array}{l}\text { Panel B: Common factor variance } \\
\text { January } 1926 \text {-December } 2000\end{array}$} \\
\hline Coefficient & -5.85 & .002 & .449 & .396 & -.184 & .702 & .136 & .106 & .106 & .041 \\
\hline$t$-statistic & -72.1 & 0.01 & 3.53 & 3.09 & -1.61 & 6.10 & 3.73 & 3.04 & 2.96 & 1.24 \\
\hline \multicolumn{11}{|c|}{ January 1946-December 2000} \\
\hline Coefficient & -1.54 & -7.92 & 6.45 & -3.31 & 1.52 & .161 & .139 & .126 & .096 & .059 \\
\hline$t$-statistic & -.40 & -1.12 & 1.19 & -.95 & .90 & .27 & 3.33 & 3.00 & 2.35 & 1.48 \\
\hline
\end{tabular}

Note: $\phi_{t}=g_{\phi}(t)+u_{t}, u_{t}=a_{1} u_{t-1}+a_{2} u_{t-2}+\varepsilon_{t} ; g_{\phi}(t)=$ fifth-order Chebychev polynomial in time with coefficients $b_{0}, \ldots, b_{5} ; \gamma_{t}=g_{\gamma}(\tau)+u_{t}, u_{t}=a_{1} u_{t-1}+a_{2} u_{t-2}+a_{3} u_{t-3}+a_{4} u_{t-4}+\varepsilon_{t} ; g_{\gamma}(t)=$ fifth-order Chebychev polynomial in time with coefficients $b_{0}, \ldots, b_{5}$.

residual processes. ${ }^{7}$ In Table 4, Panel A shows the coefficient estimates and their $t$-statistics, computed with White's heteroskedasticity consistent standard errors. The secular trend function $g_{\phi}(t)$ is shown as the solid line in Fig. 1a. The main feature is the upward trend beginning in the mid-1960s. This trend is still evident in the subsample estimation beginning 1946:01. The $R^{2}$ were 0.502 for the full sample and 0.526 for the subsample.

To estimate (10) under the quantile restriction, we used nearest-neighbor quantile estimation as described in Härdle and Linton (1994) with $k=61$ (two-sided) nearest neighbors, i.e., the window is a rolling 5 years. In Fig. 2a we show the results of a nonparametric quantile regression of $\psi_{t}$ on time. The graph shows the median along with the $75 \%$ and $25 \%$ quantiles. (It also shows the estimated conditional mean using the same nearest neighbor method.) The advantage of the nearest-neighbor smoothing method is that it is local, so that there is no influence from the Great Depression period to the post war period. In addition, even during a period with large outliers, the quantile smoothers should be influenced only by a substantial part

\footnotetext{
${ }^{7}$ Specifically, we computed the Ljung-Box $Q$ statistics for the residuals and found very high $p$-values uniformly across the first 36 lags. Specifically, nearly all $p$-values exceeded 0.5 , and the lowest $p$-value was 0.171 out of the 36 lags for each of the four residual series.
} 
Nearest Neighbor Quantile Regression Phi against Time
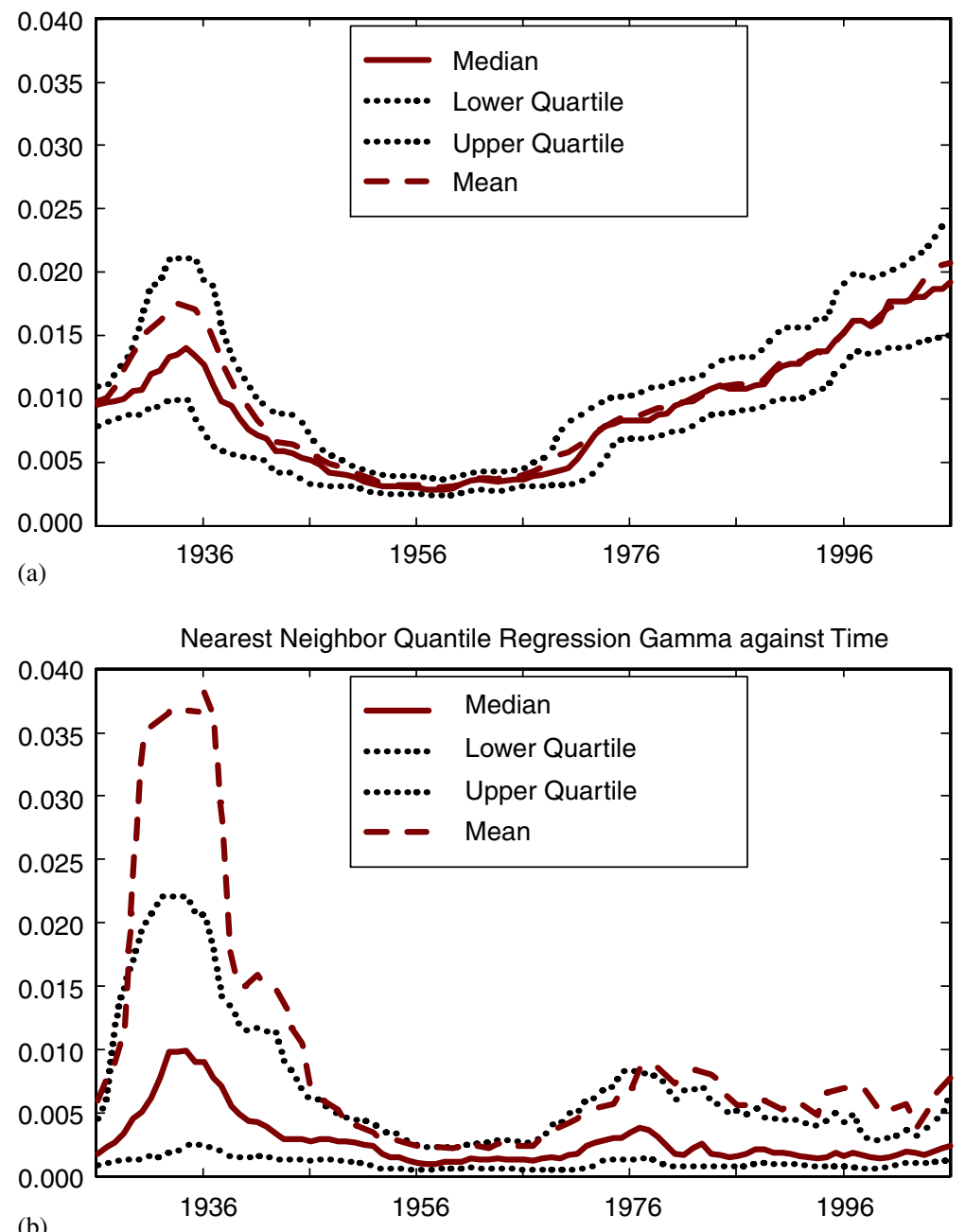

Fig. 2. (a) Shows the nearest neighbor estimated median, lower quartile, upper quartile, and mean regressions of $\phi_{t}$ on $t / T$ : The procedure uses $k=60$ nearest neighbors; (b) shows the nearest neighbor estimated median, lower quartile, upper quartile, and mean regressions of $\gamma_{t}$ on $t / T$. The procedure uses $k=60$ nearest neighbors.

of the data, not a few rogue outcomes. The main feature of this graph agrees with the results of the previous mean regressions, namely there is a strong upward trend in this component of volatility after the mid-1960s.

Next we analyze the time series heteroskedasticity in factor returns using

$$
\widehat{\gamma}_{t}=\frac{1}{n}\left(r_{t}-\widehat{\varepsilon}_{t}\right)^{\prime}\left(r_{t}-\widehat{\varepsilon}_{t}\right) .
$$


We use the same cross-section of assets for calculating $\widehat{\gamma}_{t}$ as used earlier for the estimation of $\phi_{t}$. Fig. $1 \mathrm{~b}$ shows the time series of $\widehat{\gamma}_{t}$.

As was the case for $\phi_{t}$ there is visual evidence of secular trends in $E_{t-1}\left[\log \gamma_{t}\right]$, and we use the same approach as in fitting the trend in $\log \phi_{t}$. The coefficient estimates and $t$-statistics are shown in Table 4, Panel B. The $R^{2}$ were 0.221 for the full sample and 0.164 for the subsample.

The secular trend function $g_{\gamma}(t / T)$ from the polynomial fit is shown as a black line in Fig. 1b, while in Fig. 2b we show the corresponding nearest neighbor fits. The series is dominated by the Great Depression part of the data, and there is much less evidence of an upward trend in $\gamma_{t}$ in the postwar period.

The initial impression from Figs. $1 \mathrm{a}$ and $2 \mathrm{a}$ is that the stock market has become increasingly volatile over the last 40 years. As Campbell et al. (2001) have noted and Figs. $1 \mathrm{~b}$ and $2 \mathrm{~b}$ confirm, this initial impression is misleading. During this period, market-wide index volatility has not shown an upward trend (see Schwert, 1989). Except for the Great Depression, 5-year market index volatility is fairly flat, ${ }^{8}$ as is factor volatility, $\widehat{\gamma}_{t}$. It is the cross-sectional dispersion of returns, in terms of assetspecific returns that has trended upward. As pointed out by Campbell et al. (2001), this implies an increase in the number of assets required to achieve a given level of diversification.

\subsection{Economic forces and volatility}

Officer (1973), Schwert (1989), Hamilton and Lin (1996), and Campbell et al. (2001) find that return volatility (using various measures) moves with the business cycle with higher volatility in recessions. We look at the relation between $\phi_{t}, \gamma_{t}, \psi_{t}$ (from Eq. (10)) and $\xi_{t}$ (from Eq. (17)) with six macroeconomic indicators. The first macroeconomic variable is a dummy equal to 1 during NBER dated economic expansions and 0 during economic contractions. The same macroeconomic variable is used by Campbell et al. (2001, Table VIII). The second macroeconomic variable that we use is the yield spread between long-term US government bonds and 1month Treasury bills (from Ibbotson Associates, 2003), which we call the Term Spread. The third macroeconomic series is the yield spread between Moody's Aaa and Baa rated bonds, which we call the Default Spread. Our fourth macroeconomic series is the dividend yield on the S\&P portfolio over the trailing 3 months (from Ibbotson Associates, 2003). Our remaining two macroeconomic series are available only for a shorter time period (February 1959 to December 2000). They are the experimental leading (XLI) and coincident (XCI) indicators of Stock and Watson (1989). ${ }^{9}$

\footnotetext{
${ }^{8}$ This result has been widely documented elsewhere. We have estimated trend models in a variety of other index volatility measures including equal weighted and value weighted, S\&P500, etc. and have found no significant trend in any of them.

${ }^{9}$ Updated series are available at http://ksghome.harvard.edu/ J.Stock.Academic.Ksg/xri/0206/xindex.asc.
} 
Table 5

$T$-statistics of correlations between shocks to volatility components and macroeconomic series

\begin{tabular}{|c|c|c|c|c|c|c|c|c|c|c|c|c|}
\hline \multirow[t]{2}{*}{ Lag } & \multicolumn{2}{|c|}{$\begin{array}{l}\text { NBER } \\
\text { expansion }\end{array}$} & \multicolumn{2}{|c|}{ Term spread } & \multicolumn{2}{|c|}{ Default spread } & \multicolumn{2}{|c|}{$\begin{array}{l}\text { S\&P dividend } \\
\text { yield }\end{array}$} & \multicolumn{2}{|c|}{$\begin{array}{l}\text { Experimental } \\
\text { leading }\end{array}$} & \multicolumn{2}{|c|}{$\begin{array}{l}\text { Experimental } \\
\text { coincident }\end{array}$} \\
\hline & $\psi_{t}$ & $\xi_{t}$ & $\psi_{t}$ & $\xi_{t}$ & $\psi_{t}$ & $\xi_{t}$ & $\psi_{t}$ & $\xi_{t}$ & $\psi_{t}$ & $\xi_{t}$ & $\psi_{t}$ & $\xi_{t}$ \\
\hline-12 & -0.21 & 0.83 & 0.98 & 0.24 & 0.18 & 1.52 & -0.27 & 0.86 & -0.71 & -0.20 & -0.13 & -0.04 \\
\hline-11 & -0.27 & 0.81 & 1.67 & 0.42 & 0.60 & 1.22 & -0.66 & -0.18 & -0.44 & -0.16 & 0.00 & -0.02 \\
\hline-10 & -0.30 & 0.48 & 1.16 & 1.25 & 0.89 & 1.31 & -0.27 & -1.16 & -0.24 & -0.64 & -0.27 & 0.16 \\
\hline-9 & -0.57 & 0.21 & 1.40 & 0.81 & 0.84 & 1.43 & 0.03 & -0.98 & -0.60 & -0.91 & -0.18 & 0.07 \\
\hline-8 & -0.66 & 0.03 & 0.96 & 0.87 & 0.87 & 1.91 & 0.15 & 0.12 & -0.29 & -0.64 & -0.20 & 0.09 \\
\hline-7 & -0.45 & -0.57 & 0.36 & 1.28 & 0.93 & 2.36 & 0.21 & 0.78 & -0.11 & -1.20 & -0.24 & 0.09 \\
\hline-6 & -0.21 & -1.32 & 0.24 & 1.08 & 1.02 & 2.12 & -0.93 & 0.99 & -0.53 & -1.14 & -0.20 & 0.13 \\
\hline-5 & -0.30 & -2.42 & 0.36 & 0.18 & 0.48 & 1.77 & -1.37 & 0.24 & -0.49 & -1.67 & -0.25 & 0.09 \\
\hline-4 & 0.06 & -2.60 & 0.54 & 0.66 & 0.54 & 1.62 & -1.61 & 0.39 & -0.47 & -2.63 & -0.22 & 0.07 \\
\hline-3 & 0.24 & -3.17 & 0.96 & 0.24 & 0.78 & 1.80 & -0.57 & 0.15 & 0.00 & -3.26 & -0.25 & 0.04 \\
\hline-2 & 0.93 & -3.66 & 0.69 & -0.57 & 1.26 & 1.80 & 0.18 & 1.44 & 0.29 & -3.56 & -0.27 & 0.09 \\
\hline-1 & 1.53 & -4.41 & 0.48 & -0.18 & 1.41 & 1.98 & 0.54 & 1.68 & 0.47 & -3.92 & -0.34 & 0.20 \\
\hline 0 & 1.08 & -4.29 & -0.24 & -1.47 & 1.26 & 2.34 & 0.30 & 1.80 & 0.67 & -4.12 & -0.38 & 0.27 \\
\hline 1 & 1.32 & -4.44 & 1.50 & -1.32 & 0.84 & 2.43 & -0.12 & 0.57 & 0.98 & -4.45 & -0.38 & 0.29 \\
\hline 2 & 0.06 & -3.72 & 0.60 & -0.66 & 0.63 & 1.92 & -0.03 & -0.27 & 1.14 & -4.74 & -0.38 & 0.25 \\
\hline 3 & 0.81 & -4.46 & 1.17 & -2.61 & 0.81 & 1.44 & 0.39 & 0.03 & 0.69 & -4.11 & -0.34 & 0.29 \\
\hline 4 & 0.42 & -3.95 & 0.54 & -2.75 & 0.99 & 1.08 & 0.69 & 1.20 & 0.04 & -3.66 & 0.36 & 0.27 \\
\hline 5 & -0.06 & -3.83 & 0.51 & -1.41 & 1.20 & 0.51 & 0.75 & 1.70 & 0.18 & -2.97 & -0.33 & 0.29 \\
\hline 6 & -0.57 & -3.14 & 2.15 & -2.24 & 0.99 & 0.18 & -0.18 & 1.67 & 0.16 & -2.34 & -0.29 & 0.31 \\
\hline 7 & -0.21 & -3.32 & 1.11 & -2.00 & 0.99 & 0.24 & -0.81 & 0.84 & 0.22 & -2.20 & -0.29 & 0.29 \\
\hline 8 & -0.15 & -3.29 & 1.70 & -1.91 & 1.25 & -0.24 & -0.81 & 0.30 & 0.29 & -2.11 & -0.33 & 0.36 \\
\hline 9 & -0.15 & -2.54 & 1.67 & -1.70 & 1.31 & -0.06 & -0.09 & -0.42 & -0.02 & -1.40 & -0.29 & 0.38 \\
\hline 10 & -0.48 & -2.48 & 0.24 & -1.43 & 1.04 & 0.15 & 0.63 & 0.12 & -0.89 & -0.47 & -0.27 & 0.35 \\
\hline 11 & -0.72 & -2.39 & 0.36 & -2.18 & 0.83 & 0.21 & 0.54 & 0.15 & -0.58 & -0.22 & -0.22 & 0.29 \\
\hline 12 & -0.72 & -2.47 & 1.13 & -3.16 & 0.66 & -0.18 & 0.27 & 0.24 & -0.73 & -0.35 & -0.24 & 0.35 \\
\hline
\end{tabular}

Note: $\operatorname{Corr}\left(X_{t}\right.$, Macro $\left._{t-\text { lag }}\right)$ where $X_{t}=\psi_{t}$ (shocks to $\phi_{t}$ from Eq. (10)) and $\xi_{t}$ (shocks to $\gamma_{t}$ from Eq. (16)). $\mathrm{Macro}_{t-\mathrm{lag}}=$ an NBER business cycle dummy variable; the term spread between the yields on long- and short-term Government bonds; the default spread between the yields on Baa and Aaa Corporate bonds; the S\&P composite dividend yield; the Stock and Watson experimental leading indicator-XLI; and the Stock and Watson experimental coincident indicator-XCI. Boldface entries have $t$-statistics greater than 2.0 .

Both $\phi_{t}$ and $\gamma_{t}$ have statistically significant cross-correlations with the economic variables (except for the correlations between $\phi_{t}$ and the NBER variable). ${ }^{10}$ However, much of this correlation for $\phi_{t}$ is due to the predictable component since the cross-correlations between the innovations and the macroeconomic series (discussed in detail below) are not significant. The innovations in $\gamma_{t}$ are significantly cross-correlated with a number of the macroeconomic series.

In Table 5 we show the $t$-statistics for the cross correlations (for lags of 12 months to leads of 12 months) between several macroeconomic series and shocks to volatility components $\psi_{t}$ (from Eq. (10)) and $\xi_{t}$ (from Eq. (17)). Shocks to the common

\footnotetext{
${ }^{10}$ The results for $\phi_{t}$ and $\gamma_{t}$ are not shown but are available from the authors on request.
} 
volatility of asset-specific returns, $\psi_{t}$, are not significantly related to the levels of the macroeconomic series. However, shocks to the common factor volatility, $\xi_{t}$, are significantly positively correlated with the default spread and significantly negatively related to the levels of an NBER expansion dummy variable, the US Treasury term spread, and the experimental leading index.

We find that shocks to common asset-specific volatility, $\psi_{t}$, are not significantly correlated with leads or lags of the NBER indicator. The factor volatility shock, $\xi_{t}$, is significantly negatively correlated with lags of the NBER dummy and with leads of up to five months. The results are generally consistent with the negative correlations between volatility and the NBER dummy found by Campbell et al. (2001). Our results show that this relationship is much stronger for factor volatility than for common asset-specific volatility (Campbell et al. do not separate the components). We calculate Ljung-Box $Q$-statistics (see Greene, 2000, p. 542) to test hypotheses that correlations are jointly zero for lags and leads $1-3,1-6,1-9$ and $1-12$. These are shown in Table 6. They are all insignificant for the correlations of the NBER dummy with $\psi_{t}$, and are all significant for correlations with $\xi_{t}$.

Table 5 shows that there is almost uniformly positive correlation at all leads and lags between the Term Spread and $\psi_{t}$. The correlations are generally insignificant as are the Ljung-Box statistics. In contrast, shocks to factor volatility, $\xi_{t}$, are negatively correlated with lagged values of the Term Spread (and leads up to two months). Many of these negative correlations are significant. The $Q$-statistics reject the hypothesis that correlations are jointly zero for all of the lag combinations.

All of the correlations between $\psi_{t}$ and $\xi_{t}$ and the Default Spread, except one, are positive. There is uniformly positive correlation at all leads and lags between the Default Spread and $\psi_{t}$. The individual and joint test for correlations are insignificant. Shocks to factor volatility, $\xi_{t}$, are generally positively correlated with lags and leads of the Default Spread. The correlations are individually significant for lags 1 and 0 as well as for leads 6 and 7. The $Q$-statistics reject the hypothesis that correlations are jointly zero for of the lag combinations of 1-3 months and 1-6 months. All lead combinations tested are significantly different from zero.

The correlations between $\psi_{t}$ and $\xi_{t}$ and the S\&P dividend yield are individually and jointly insignificant. There is positive, but statistically insignificant, correlation between $\psi_{t}$ and XLI at all leads and lags. There is negative correlation between $\xi_{t}$ and XLI at all leads and lags. These are individually significant from lags of eight months to leads of four months and jointly significant for all combinations tested in Table 6. Neither $\psi_{t}$ nor $\xi_{t}$ are significantly correlated with the coincident index (XCI).

\subsection{Purely asset specific volatility dynamics}

To analyze the purely asset-specific component of dynamic heteroskedasticity, we estimate individual GARCH, GJR and EGARCH models on scaled asset specific returns, $\eta_{i t}=\phi_{t}^{-1 / 2} \varepsilon_{i t}$. We limit this part of the analysis to assets with at least 90 months of continuous return observations, which decreases the total number of assets to 7054. In view of the large number of assets we cannot do an asset by asset 
Table 6

Ljung-Box statistics for joint significance across lags of Correlations between volatility components and macroeconomic series

\begin{tabular}{|c|c|c|c|c|}
\hline \multirow[t]{2}{*}{ Lag } & \multicolumn{2}{|l|}{$\psi_{t}$} & \multicolumn{2}{|l|}{$\xi_{t}$} \\
\hline & $L-B$ & $p$-value & $L-B$ & $p$-value \\
\hline
\end{tabular}

Correlations with NBER

-1 to -12

-1 to -9

-1 to -6

-1 to -3

1 to 3

1 to 6

1 to 9

1 to 12

\subsection{8}

4.357

3.376

3.244

2.447

2.936

3.031

4.317

Correlations with $S \& P$ dividend yield

-1 to -12

$$
6.730
$$

6.165

-1 to -9

6.097

-1 to -3

0.648

1 to 3

0.169

1 to 6

1.256

2.576

1 to 12
0.971

0.886

0.760

0.355

0.485

0.817

0.963

0.977

0.875

0.723

0.412

0.885

0.982

0.974

0.979

0.993
59.471

$\mathbf{5 7 . 8 9 8}$

57.509

42.905

53.357

93.644

122.327

140.716

9.987

7.796

6.191

4.964

0.408

7.670

8.618

8.715

6.978

0.859

10.444

5.183

0.577

0.818

2.087

0.912

1.600

0.660

4.011

9.296

16.430

17.928
0.260

0.158

0.058

0.118
5.130

2.017

0.823

0.416

9.052

23.830

34.537

51.684
0.000

0.000

0.000

0.000

0.000

0.000

0.000

0.000

0.617

0.555

0.402

0.174

0.939

0.263

0.473

0.727

Correlations with experimental leading index

$\begin{array}{ll}2.360 & 0.999 \\ 1.542 & 0.997 \\ 1.086 & 0.982 \\ 0.316 & 0.957 \\ 2.844 & 0.416 \\ 2.903 & 0.821 \\ 3.041 & 0.963 \\ 4.769 & 0.965\end{array}$

$\mathbf{5 3 . 5 8 0}$

0.000

53.090

50.328

$\mathbf{0 . 0 0 0}$

39.080

0.000

59.951

$\mathbf{0 . 0 0 0}$

88.330

$\mathbf{0 . 0 0 0}$

100.020

0.000

100.451

0.000

0.000

Correlations with default spread

$\begin{array}{ll}9.303 & 0.677 \\ 8.091 & 0.525 \\ 5.776 & 0.449\end{array}$


Table 6 (continued)

\begin{tabular}{|c|c|c|c|c|}
\hline \multirow[t]{2}{*}{ Lag } & \multicolumn{2}{|l|}{$\psi_{t}$} & \multicolumn{2}{|l|}{$\xi_{t}$} \\
\hline & $L-B$ & $p$-value & $L-B$ & $p$-value \\
\hline & 4.226 & 0.238 & 10.297 & 0.016 \\
\hline & 1.726 & 0.631 & 11.617 & 0.009 \\
\hline & 5.176 & 0.521 & 13.089 & 0.042 \\
\hline & 9.494 & 0.393 & 13.209 & 0.153 \\
\hline & 11.761 & 0.465 & 13.308 & 0.347 \\
\hline \multicolumn{5}{|c|}{ Correlations with experimental coincident index } \\
\hline & 0.632 & 1.000 & 0.144 & 1.000 \\
\hline & 0.543 & 1.000 & 0.112 & 1.000 \\
\hline & 0.405 & 0.999 & 0.090 & 1.000 \\
\hline & 0.253 & 0.969 & 0.057 & 0.996 \\
\hline & 0.404 & 0.939 & 0.240 & 0.971 \\
\hline & 0.728 & 0.994 & 0.500 & 0.998 \\
\hline & 1.012 & 0.999 & 0.870 & 1.000 \\
\hline & 1.201 & 1.000 & 1.224 & 1.000 \\
\hline
\end{tabular}

Note: $\operatorname{Corr}\left(X_{t}\right.$, Macro $\left._{t-\text { lag }}\right) X_{t}=\psi_{t}$ (shocks to $\phi_{t}$ from Eq. (10)) and $\xi_{t}$ (shocks to $\gamma_{t}$ from Eq. (16)). Macro $_{t-\text { lag }}=$ an NBER business cycle dummy variable; the term spread between the yields on long- and short-term Government bonds; the default spread between the yields on Baa and Aaa Corporate bonds; the S\&P composite dividend yield; the Stock and Watson experimental leading indicator-XLI; and the Stock and Watson experimental coincident indicator-XCI.

model specification search, so instead just estimate each of the individual models for each asset $i=1, \ldots, n$ using asset-by-asset maximum likelihood and then report goodness-of-fit and other outcomes. We estimate the parameters assuming normally distributed innovations, and then alternatively assuming a $t$-density where the degrees of freedom of the $t$-density appears as an additional parameter (Bollerslev, 1987).

For the GARCH and GJR models we use the Engle and Sheppard (2001) target variance approach to estimate the intercept coefficient. That is, we transform the GARCH model (14) into $h_{i t}=\omega_{0 i}+\omega_{1 i}\left(h_{i t-1}-\omega_{0 i}\right)+\omega_{2 i}\left(\eta_{i t-1}^{2}-\omega_{0 i}\right)$, which leaves the model unchanged except for the definition of the intercept coefficient. Note that in this form the intercept is the unconditional variance. The transform of the GJR model (15) is straightforward, by analogy. We then use the sample variance as the estimate of $\omega_{0 i}$. This removes the intercept coefficient from the nonlinear estimation routine. We find that using this target variance approach improves estimation reliability. There is no obvious way to implement the target variance approach for the EGARCH model so we do not attempt it. Each model is estimated using the Berndt-Hall-Hall-Hausman maximization routine. In the maximization routine we impose the nonnegativity constraints required to ensure nonnegative variance; for GARCH, this is $\omega_{0 i}, \omega_{1 i}, \omega_{2 i} \geqslant 0$; for GJR, $\omega_{0 i}, \omega_{1 i}, \omega_{2 i}, \omega_{3 i} \geqslant 0$, there is no restriction needed for EGARCH. We do not impose the additional conditions for weak stationarity. 
Table 7

Comparative performance of GARCH, Glosten-Jagannathan-Runkle and EGARCH models, using both normal and $t$-density for the innovations

\begin{tabular}{|c|c|c|c|c|c|c|c|}
\hline & \multirow[t]{2}{*}{$\%$ Converged } & \multirow[t]{2}{*}{$\%$ Stationary } & \multicolumn{3}{|c|}{ Mean absolute error (MAE) } & \multirow{2}{*}{$\begin{array}{l}\% \text { Assets } \\
\text { lowest } \\
\text { MAE }\end{array}$} & \multirow{2}{*}{$\begin{array}{l}\% \text { Assets } \\
\text { highest } \\
\text { MAE }\end{array}$} \\
\hline & & & $\begin{array}{l}\text { Lower } \\
\text { quartile }\end{array}$ & Median & $\begin{array}{l}\text { Upper } \\
\text { quartile }\end{array}$ & & \\
\hline GARCH & 99.9 & 97.1 & 1.58 & 2.97 & 5.92 & 0.1 & 5.8 \\
\hline$t$-density-GARCH & 99.6 & 98.0 & 1.62 & 3.11 & 6.19 & 0.1 & 38.7 \\
\hline GJR & 89.4 & 89.1 & 1.41 & 2.61 & 5.09 & 21.7 & 21.5 \\
\hline$t$-density-GJR & 93.3 & 92.3 & 1.33 & 2.45 & 4.69 & 16.8 & 12.5 \\
\hline EGARCH & 96.0 & 91.0 & 1.58 & 3.03 & 6.43 & 0.5 & 30.0 \\
\hline t-density-EGARCH & 95.4 & 93.6 & 1.18 & 2.16 & 4.04 & 61.0 & 0.3 \\
\hline
\end{tabular}

Table 7 compares the performance of the models by calculating, for each model and for each asset, the mean absolute error (MAE). This is found by treating the implied volatility $\widehat{h}_{i t}$ as a prediction of the squared residual, $\eta_{i t}^{2}$, taking the absolute value of the difference, and then taking the mean over the sample period (the sample periods differ across assets but are always at least 90 months long). In Table 7 we show the median and interquartile range of these MAEs across assets. ${ }^{11}$ For each asset we also calculate which of the six model choices had the lowest and highest MAE. In some cases the estimation routine did not converge, or gave estimates which imply covariance nonstationarity; the percentages of these two cases are also shown in Table 7. The MAE calculations are done for the intersection of assets where the estimation routine converged for all six models. The best fitting of the six models is the EGARCH model with a $t$-density. It has the lowest interquartile range, lowest median, best fit for the largest percentage of assets, and worst fit for the smallest percentage of assets. The GARCH model with a $t$-density is the worst fitting by all criteria except the upper border of the interquartile range, where the EGARCH with a normal density has a slightly higher value.

Table 8 Panel A shows the median and interquartile range of all the coefficient estimates, and Panel B does the same for the $t$-statistics of these coefficients. For all three models, the estimated degrees of freedom of the $t$-density is low, indicating considerable positive excess kurtosis. (Note that the $t$-statistic of the degrees of freedom parameter shown in Panel B is not intended as a test for the degrees of freedom equal to zero, since this is not an allowable value for the degrees of freedom; the $t$-statistic in this case should be viewed simply as the coefficient estimate divided by its standard error.)

The GJR model only differs from a GARCH model if the coefficient $\omega_{3 i}$ differs from $\omega_{2 i}$. The usual empirical finding is a larger volatility effect from a negative return than from a positive return of equal magnitude, which implies $\omega_{2 i}>\omega_{3 i}$. There

\footnotetext{
${ }^{11} \mathrm{We}$ report median values where possible so as to mitigate any problem with survivorship sample selection.
} 
Table 8

Coefficient estimates for GARCH, Glosten-Jagannathan-Runkle and EGARCH models, using both normal and $t$-density for the innovations

\begin{tabular}{|c|c|c|c|c|c|c|c|}
\hline & & $\omega_{0}$ & $\omega_{1}$ & $\omega_{2}$ & $\omega_{3}$ & $\omega_{2}-\omega_{3}$ & DF \\
\hline \multicolumn{8}{|l|}{ Panel A: Coefficients } \\
\hline \multirow[t]{3}{*}{ GARCH } & Lower quartile & 1.29 & .070 & .043 & - & - & - \\
\hline & Median & 2.35 & .428 & .161 & - & - & - \\
\hline & Upper quartile & 4.40 & .702 & .336 & - & - & - \\
\hline \multirow[t]{3}{*}{$t$-density-GARCH } & Lower quartile & 1.29 & .041 & .376 & - & - & 3.34 \\
\hline & Median & 2.35 & .221 & .615 & - & - & 4.15 \\
\hline & Upper quartile & 4.38 & .471 & .781 & - & - & 5.60 \\
\hline \multirow[t]{3}{*}{ GJR } & Lower quartile & 1.28 & .187 & .000 & .000 & -.062 & - \\
\hline & Median & 2.33 & .454 & .076 & .048 & .008 & - \\
\hline & Upper quartile & 4.35 & .565 & .203 & .132 & .134 & - \\
\hline \multirow[t]{3}{*}{$t$-density-GJR } & Lower quartile & 1.28 & .168 & .131 & .002 & .048 & .673 \\
\hline & Median & 2.33 & .433 & .277 & .028 & .200 & 1.49 \\
\hline & Upper quartile & 4.34 & .660 & .479 & .132 & .425 & 3.58 \\
\hline \multirow[t]{3}{*}{ EGARCH } & Lower quartile & .001 & -.233 & .000 & -.269 & - & - \\
\hline & Median & .173 & 495 & .263 & .261 & - & - \\
\hline & Upper quartile & .813 & .854 & .574 & .735 & - & - \\
\hline \multirow[t]{3}{*}{$t$-density-EGARCH } & Lower quartile & -.438 & .088 & .000 & -.204 & - & 2.43 \\
\hline & Median & -.137 & .687 & .116 & .251 & - & 2.86 \\
\hline & Upper quartile & -.012 & .883 & .222 & .684 & - & 3.49 \\
\hline \multicolumn{8}{|l|}{ Panel B: $t$-statistics } \\
\hline \multirow[t]{3}{*}{ GARCH } & Lower quartile & - & 0.79 & 0.37 & - & - & - \\
\hline & Median & - & 2.47 & 1.27 & - & - & - \\
\hline & Upper quartile & - & 6.83 & 2.53 & - & - & - \\
\hline \multirow[t]{3}{*}{$t$-density-GARCH } & Lower quartile & - & 0.20 & 1.30 & - & - & 3.46 \\
\hline & Median & - & 0.68 & 2.27 & - & - & 3.92 \\
\hline & Upper quartile & - & 1.67 & 3.73 & - & - & 4.47 \\
\hline \multirow[t]{3}{*}{ GJR } & Lower quartile & - & 0.50 & 0.00 & 0.04 & -0.84 & - \\
\hline & Median & - & 1.63 & 0.40 & 0.30 & -0.14 & - \\
\hline & Upper quartile & - & 8.45 & 1.08 & 0.74 & 0.39 & - \\
\hline \multirow[t]{3}{*}{$t$-density-GJR } & Lower quartile & - & 0.42 & 0.45 & 0.03 & 0.67 & 0.20 \\
\hline & Median & - & 1.06 & 0.83 & 0.16 & 0.99 & 0.92 \\
\hline & Upper quartile & - & 2.09 & 1.46 & 0.43 & 3.09 & 4.36 \\
\hline
\end{tabular}


Table 8 (continued)

\begin{tabular}{llllllll}
\hline & & $\omega_{0}$ & $\omega_{1}$ & $\omega_{2}$ & $\omega_{3}$ & $\omega_{2}-\omega_{3}$ & DF \\
\hline EGARCH & Lower quartile & & -0.57 & 0.00 & -0.83 & - & - \\
& Median & - & 1.42 & 1.15 & 0.84 & - & - \\
& Upper quartile & - & 4.39 & 2.65 & 2.61 & - & - \\
& & & & & & & \\
$t$-density-EGARCH & Lower quartile & - & 0.16 & 0.00 & -0.66 & - & 4.31 \\
& Median & - & 1.71 & 0.35 & 0.84 & - & 6.14 \\
& Upper quartile & - & 3.41 & 0.67 & 2.60 & - & \\
\hline
\end{tabular}

Note: The volatility models are: GARCH $-h_{t}=\omega_{0}+\omega_{1}\left(h_{t-1}-\omega_{0}\right)+\omega_{2}\left(\varepsilon_{t-1}^{2}-\omega_{0}\right) ;$ GJR $-h_{t}=\omega_{0}+$ $\omega_{1}\left(h_{t-1}-\omega_{0}\right)+\omega_{2}\left(\varepsilon_{t-1}^{2}-\omega_{0}\right) \delta\left\{\varepsilon_{t-1}<0\right\}+\omega_{3}\left(\varepsilon_{t-1}^{2}-\omega_{0}\right) \delta\left\{\varepsilon_{t-1} \geqslant 0\right\} ; \operatorname{EGARCH}-\log \left(h_{t}\right)=\omega_{0}+\omega_{1} \log \left(h_{t-1}\right)+$ $\omega_{2}\left(\left|\varepsilon_{t-1} / h_{t-1}\right|-\omega_{3}\left(\varepsilon_{t-1} / h_{t-1}\right)\right)$; DF- estimated degrees of freedom of the $t$-density of the innovations.

is some evidence for this asymmetry, although the difference is not usually significant on an asset-by-asset basis. In the EGARCH model, larger volatility effects associated with negative returns is implied by $\omega_{4 i}>0$. Again, there is some evidence for this type of asymmetry.

\section{Conclusion}

In an approximate factor model, the random return of each asset is divided into factor-related return and asset-specific return. Given a factor model, the time-series heteroskedasticity of individual asset returns can be represented with three components: a factor-related, common asset-specific, and purely asset-specific component. We develop and estimate a heteroskedastic factor model for monthly US equity returns with this three-component structure.

Each of the three components is modeled separately. For the common assetspecific component, we develop a univariate stochastic volatility model. For the factor component we develop a new multivariate GARCH model that reduces in estimation to a univariate GARCH-type model and is invariant to factor rotations. For the purely asset-specific component we use a cross-section of GARCH-type models.

We find that all three components contribute to the heteroskedasticity of individual asset returns. We find that both factor variance and common asset-specific variance have secular trends. Both components are very high in the Great Depression and then decline until the mid-1950s. After that, common asset-specific variance shows a long steady increase.

Previous authors have shown that return volatility (using various measures) moves with the business cycle with higher volatility in recessions. Using our factor model decomposition, we extend these existing results. The innovations in factor-related volatility have negative correlation with a expansion indicator (a dummy variable which has value one in NBER-dated expansions and zero elsewhere), positive 
correlation with the term premium and default premium in bond yields, and positive correlation with average dividend yield. The innovations in common asset-specific volatility do not have any clearly strong links to the business cycle or yield variates. A theoretical explanation for these observed patterns, whether a rational-choicebased theory or a behavioral theory, would be a notable contribution.

Our asset-by-asset analysis of scaled asset-specific return shows that there is also an empirically identifiable purely asset-specific component to dynamic volatility. It might be interesting to examine whether the dynamic process of purely asset-specific volatility is related to dynamic information releases and/or trading volume of each particular asset.

\section{Acknowledgements}

We would like to thank Heather Anderson, John Campbell, Frank Diebold, Serena $\mathrm{Ng}$, and two referees as well as seminar participants at the University of Cambridge, the London School of Economics, ECARES, Bruxelles, and the Common Features in Rio conference for helpful comments. We also thank Christian Huse for research assistance and the Financial Markets Group for financial support.

\section{References}

Ahn, S.C., Lee, Y.H., Schmidt, P., 2001. GMM estimation of linear panel data models with time-varying individual effects. Journal of Econometrics 101, 219-255.

Bai, J., 2003. Inferential theory for factor models of large dimension. Econometrica 71, 135-171.

Bai, J., Ng, S., 2002. Determining the number of factors in approximate factor models. Econometrica 70, 191-221.

Bollerslev, T., 1986. Generalized autoregressive conditional heteroskedasticity. Journal of Econometrics 31, 307-327.

Bollerslev, T., 1987. A conditional heteroskedastic time series model for speculative prices and rates of return. Review of Economics and Statistics 69, 542-547.

Campbell, J.Y., Lettau, M., Malkiel, B.G., Xu, Y., 2001. Have individual stocks become more volatile? An empirical exploration of idiosyncratic risk. Journal of Finance 61, 1-43.

Carrasco, M., Chen, X., 2002. Mixing and moment properties of various GARCH and stochastic volatility models. Econometric Theory 18, 17-39.

Chamberlain, G., Rothschild, M.R., 1983. Arbitrage and mean-variance analysis on large asset markets. Econometrica 51, 1281-1304.

Connor, G., Korajczyk, R.A., 1986. Performance measurement with the Arbitrage Pricing Theory: a new framework for analysis. Journal of Financial Economics 15, 373-394.

Connor, G., Korajczyk, R.A., 1987. Estimating pervasive economic factors with missing observations. Working Paper no. 34, Department of Finance, Northwestern University.

Connor, G., Korajczyk, R.A., 1988. Risk and return in an equilibrium APT: application of a new test methodology. Journal of Financial Economics 21, 255-289.

Connor, G., Korajczyk, R.A., 1993. A test for the number of factors in an approximate factor model. Journal of Finance 48, 1263-1291.

Diebold, F.X., Nerlove, M., 1989. The dynamics of Exchange rate volatility: a multivariate latent factor ARCH model. Journal of Applied Econometrics 4, 1-21.

Engle, R.F., 1987. Multivariate ARCH with factor structures - cointegration in variance. University of California at San Diego, Mimeo. 
Engle, R.F., Sheppard, K., 2001. Theoretical and empirical properties of dynamic conditional correlation multivariate GARCH. NBER Working Paper no. w8554.

Forni, M., Reichlin, L., 1998. Let's get real: a factor analytic approach to disaggregated business cycle dynamics. Review of Economic Studies 65, 453-473.

Forni, M., Hallin, M., Lippi, M., Reichlin, L., 2000. The generalized dynamic factor model: identification and estimation. Review of Economics and Statistics 82, 540-554.

Glosten, L.R., Jagannathan, R., Runkle, D.E., 1993. On the relation between the expected value and the volatility of the nominal excess return on stocks. Journal of Finance 48, 1779-1801.

Greene, W.H., 2000. Econometric Analysis, 4th ed. Prentice-Hall, Upper Saddle River, NJ.

Härdle, W., Linton, O.B., 1994. Applied nonparametric methods. In: McFadden, D., Engle, R. (Eds.), The Handbook of Econometrics, vol. IV. North Holland, Amsterdam.

Hamilton, J.D., Lin, G., 1996. Stock market volatility and the business cycle. Journal of Applied Econometrics 11, 573-593.

Ibbotson Associates, 2003. Stocks Bonds, Bills, and Inflation: 2003 Yearbook (Ibbotson Associates, Chicago, IL).

ITG, Inc., 2002. ITG Risk Models, Version 2.1 (ITG, Inc., New York).

Jones, C.S., 2001. Extracting factors from heteroskedastic asset returns. Journal of Financial Economics $62,293-325$.

Nelson, D.B., 1991. Conditional heteroskedasticity in asset returns: a new approach. Econometrica 59, $347-370$.

Officer, 1973. The variability of the market factor of the New York Stock Exchange. Journal of Business $67,807-812$.

Pesaran, M.H., 2002. Estimation and Inference in Large Heterogenous Panels with Cross Section Dependence. Cambridge University, Mimeo.

Phillips, P.C.B., Moon, H.R., 1999. Linear regression limit theory for nonstationary panel data. Econometrica 67, 1057-1113.

Schwert, G.W., 1989. Why does stock market volatility change over time? Journal of Finance 44, $1115-1153$.

Scott, L.O., 1988. An extension of the asymptotic principal components method for estimating approximate factor structures. Working paper, University of Illinois, Urbana-Champaign.

Sentana, E., 1998. The relation between conditionally heteroskedastic factor models and factor GARCH models. Econometrics Journal 1, 1-9.

Stock, J.H., Watson, M.W., 1989. New indexes of coincident and leading economic indicators. NBER Macroeconomics Annual, National Bureau of Economic Research, Cambridge, MA. 